\title{
EULAR Recommendations 2003: an evidence based approach to the management of knee osteoarthritis: Report of a Task Force of the Standing Committee for International Clinical Studies Including Therapeutic Trials (ESCISIT)
}

\author{
K M Jordan, N K Arden, M Doherty, B Bannwarth, J W J Bijlsma, P Dieppe, K Gunther, \\ H Hauselmann, G Herrero-Beaumont, P Kaklamanis, S Lohmander, B Leeb, M Lequesne, \\ B Mazieres, E Martin-Mola, K Pavelka, A Pendleton, L Punzi, U Serni, B Swoboda, G Verbruggen, \\ I Zimmerman-Gorska, M Dougados
}

See end of article for authors' affiliations

Correspondence to: Professor M Dougados, Institut de Rhumatologie, Hardy B, Hopital Cochin 27, rue du Faubourg SaintJacques, 75014 Paris,

France; m.doug@cch. ap-hop-paris.fr

Accepted 21 July 2003

\begin{abstract}
Objectives: To update the EULAR recommendations for management of knee osteoarthritis (OA) by an evidence based medicine and expert opinion approach.

Methods: The literature search and guidelines were restricted to treatments for knee OA pertaining to clinical and/or radiological OA of any compartment of the knee. Papers for combined treatment of knee and other types of OA were excluded. Medline and Embase were searched using a combination of subject headings and key words. Searches for those treatments previously investigated were conducted for January 1999 to February 2002 and for those treatments not previously investigated for 1966 to February 2002. The level of evidence found for each treatment was documented. Quality scores were determined for each paper, an effect size comparing the treatment with placebo was calculated, where possible, and a toxicity profile was determined for each treatment modality.

Results: 497 new publications were identified by the search. Of these, 103 were intervention trials and included in the overall analysis, and 33 treatment modalities were identified. Previously identified publications which were not exclusively knee OA in the initial analysis were rejected. In total, 545 publications were included. Based on the results of the literature search and expert opinion, 10 recommendations for the treatment of knee OA were devised using a five stage Delphi technique. Based on expert opinion, a further set of 10 items was identified by a five stage Delphi technique as important for future research.

Conclusion: The updated recommendations support some of the previous propositions published in 2000 but also include modified statements and new propositions. Although a large number of treatment options for knee OA exist, the evidence based format of the EULAR Recommendations continues to identify key clinical questions that currently are unanswered.
\end{abstract}

O steoarthritis (OA) is the most common form of arthritis in Western populations. It is characterised pathologically by both focal loss of articular cartilage and marginal and central new bone formation. OA of the knee, the principal large joint to be affected, results in disabling knee symptoms in an estimated $10 \%$ of people older than 55 years, a quarter of whom are severely disabled. ${ }^{1}$ The risk of disability attributable to knee OA alone is as great as that due to cardiac disease and greater than that due to any other medical disorder in the elderly. ${ }^{2}$ A recent World Health Organisation report on the global burden of disease indicates that knee OA is likely to become the fourth most important global cause of disability in women and the eighth most important in men. ${ }^{3}$ The annual costs attributable to knee OA are immense. There is therefore a burden on health from both morbidity and cost. Radiographic evidence of knee OA in men and women aged over 65 is reported in 30\% of subjects, ${ }^{4}$ around one third of whom are symptomatic. Annual arthroplasty rates in Europeans over the age of 65 vary from country to country but are of the order of $0.5-0.7$ per $1000 . .^{5}$

The aetiology of knee OA is multifactorial and includes both generalised constitutional factors (for example, aging, sex, obesity, heredity, reproductive variables) and local adverse mechanical factors (for example, trauma, occupational and recreational usage, alignment). ${ }^{67}$ There is a significant genetic component to the prevalence of knee OA, with heritability estimates from twin studies of $0.39-0.65$ independent of known environmental or demographic confounders. ${ }^{8}$

Knee OA is associated with symptoms of pain and functional disability. Physical disability arising from pain and loss of functional capacity reduces quality of life and increases the risk of further morbidity and mortality. Current treatments aim at alleviating these symptoms by several different methods:

- Non-pharmacological treatments (for example, education, exercise, lifestyle changes)

- Pharmacological treatments (for example, paracetamol, non-steroidal anti-inflammatory drugs (NSAIDs), topical treatments)

Abbreviations: ES, effect size; $H A$, hyaluronic acid; NSAIDs, nonsteroidal anti-inflammatory drugs; OA, osteoarthritis; $Q S$, quality score; $\mathrm{RCT}$, randomised controlled trial; TKR, total knee replacement 
- Invasive interventions (for example, intra-articular injections, lavage, arthroplasty).

The objectives of management are to:

- Educate the patient about OA and its management

- Alleviate pain

- Improve function and decrease disability

- Prevent or retard progression of the disease and its consequences.

Current evidence to support the various treatments in current use, however, is very variable.

Guidelines on the management of knee and hip OA have been published by the Royal College of Physicians ${ }^{9}$ and the American College of Rheumatology. ${ }^{10}$ In 1998, EULAR commissioned a steering group to review the evidence for the treatment of knee OA. Recommendations for treatment were developed as a result of this evidence based review and presented in 2000. ${ }^{11}$ These guidelines, however, were restricted to a limited number of treatment modalities and only reviewed evidence up until December 1998. We therefore have updated the recommendations by extending the literature search to February 2002 and by including all treatments used in knee OA.

\section{METHODS}

Membership of guidelines steering group committee The members of the expert committee on knee OA reconvened in November 2001 to establish the methodology in updating the evidence base and recommendations for the treatment of knee OA. The initiative, endorsed by ESCISIT, involved a committee of experts in OA ( 19 rheumatologists, four orthopaedic surgeons) and one research fellow from 13 European countries.

The aims of the committee were:

- To describe all the therapeutic modalities used in the treatment of knee OA and to review the current level of evidence attributable to each of these treatments

- To produce a list of 10 recommendations for the management of knee OA and to examine the degree to which these recommendations are supported both by research evidence and the consensus of expert opinion

- To specify 10 recommendations for the future research agenda for the management of knee OA.

\section{Evidence based review}

Search strategy

To maintain continuity from the previous search, Medline OVID and BIDS Embase were the databases searched systematically. The searches for those treatment modalities previously investigated were conducted for the period January 1999 to February 2002 and for those modalities not previously investigated from 1966 to February 2002. In the search strategy, all English and other European language publications in the form of systematic reviews, metaanalyses, randomised controlled trials (RCTs), controlled trials, and observational studies were included. Publications in non-European languages were excluded.

\section{Selection of manuscripts}

All trials that assessed the effects of a treatment for knee OA on pain and/or function were included. Thirty three such individual treatment modalities were identified; NSAIDs are divided into two subsets, conventional (non-selective) NSAIDs and COX 2 selective NSAIDs (coxibs), but overall recognised as one group (table 1). For the purpose of the review knee OA was defined as patients with clinical and/or radiological evidence of knee OA. Only papers exclusively studying knee OA were included at all stages of the analysis; those combining hip and knee OA were excluded. The previous literature search included papers combining hip and knee OA in its qualitative data; these were reviewed and if the results for hip and knee OA could not be separated from one another, the publication was rejected.

\section{Quality scoring of manuscripts}

The methodological design of each study was scored according to a predetermined proforma. ${ }^{12}$ This methodological checklist provided a quality assessment of the information provided by each individual publication, particularly addressing study design and methodology and the statistical power of each study. Studies were scored $0-1$ for 26 questions and $0-2$ for one question, giving a maximum total of 28 . Power calculations were scored as 1 if present and 0 if absent. If probability values were reported in the results, a score of 1 was given and 0 if absent. A single assessor scored English language publications and a second assessor validated these scores in a blinded fashion. Non-English European language publications were assessed by individual members of the EULAR steering group committee fluent in the language of the publication. All quality scores were collected and recorded centrally.

\section{Estimation of a treatment effect size}

Quantitative analysis of treatment effect was assessed, where possible, by calculating the effect size (ES) for validated outcome measures of pain and function. A software package was used for this purpose. ${ }^{13}$ An ES is the standardised mean difference between a treatment group and a control group for an outcome variable ${ }^{14}$-in this case, pain and function. It reflects the magnitude of difference between two groups in standardised terms and is free of units. The mean and distribution of values for the baseline placebo and active treatment, and end point placebo and active treatment, and difference from baseline to end point were tabulated for each of the outcome measures recorded.

The ES and data displayed in this paper in all cases are calculated against placebo. Clinically, an ES of 0.2 is considered small, 0.5 is moderate (and would be recognised clinically), and greater then 0.8 is large. All data were collected and recorded centrally.

\section{Categorising evidence}

Categories of evidence were adapted from the classification of the United States Agency for Health Care Policy and Research. Evidence was categorised according to study design reflecting susceptibility to bias. Table 2 shows the categories in descending order of importance. Questions posed by the recommendations were answered using the best evidence available. If, for example, a question could be answered by category 1 evidence then weaker design publications were not reviewed.

\section{Strength of recommendation}

The strength of recommendation for an intervention was graded A-D (table 3 ) by members of the editing subcommittee of the task force, after examination of the evidence in detail. The strength of recommendations is based not only on the level of evidence but also upon consideration of the following: the ES of the intervention; the side effect profile; the applicability of the evidence to the population of interest; practicality of delivery; and economic considerations. In this way the different treatments could be scored in a pragmatic manner more applicable to everyday clinical practice.

\section{Assessment by expert panel opinion}

\section{Experts' opinion approach}

After informing the expert committee about the results of the literature search and the level of evidence found for each treatment modality, two sets of 10 recommendations were 
Table 1 Treatment modalities identified for the treatment of knee OA

\begin{tabular}{llll}
\hline Non-pharmacological & Pharmacological & Intra-articular & Surgical \\
\hline Education & Paracetamol & Corticosteroid & Arthroscopy \\
Exercise & NSAIDs & Hyaluronic acid & Osteotomy \\
Insoles & Opioid analgesics & Tidal irrigation & UKR \\
Orthotic devices & Sex hormones & & TKR \\
Weight loss & SYSADOA & \\
Laser & Psychotropic drugs & \\
Spa & Topical NSAID & \\
Telephone & Topical capsaicin & \\
Vitamins/minerals & & \\
Pulsed EMF & & \\
Ultrasound & & \\
TENS & & \\
Acupuncture & & \\
Nutrients & & \\
Herbal remedies & & \\
\hline \multicolumn{2}{l}{ EMF, electromagnetic field therapy; TENS, transcutaneous electrical nerve stimulation; NSAIDs, non-steroidal anti- } \\
inflammatory drugs; SYSADOA, SYmptomatic Slow Acting Drugs for OA (includes avocado/soybean \\
unsaponifiables (ASU), chondroitin, diacerein and glucosamine); UKR, unicompartmental knee replacement; TKR, \\
total knee replacement. \\
\end{tabular}

proposed following a five stage Delphi technique:(a) the final expert evidence and opinion based recommendations for treatment, and $(b)$ recommendations for future research agendas.

\section{Toxicity profile}

Once the definitive list of the treatments and their level of evidence was communicated, the committee ranked the potential toxicity of each intervention. This was expressed as a $100 \mathrm{~mm}$ visual analogue scale, in which 0 was "not toxic at all" and 100 was "very toxic". Figure 1 shows the results obtained.

It was felt by members of the panel after the initial opinion had been sought that the NSAID group should be subdivided into conventional NSAIDs and coxibs. This was therefore performed at a later meeting.

\section{Level of evidence of the experts' opinion approach} The researchers who undertook the literature search evaluated the level of evidence in order to answer the questions posed by the 10 recommendations for management of knee $\mathrm{OA}$ as proposed by the panel.

\section{RESULTS}

\section{Evidence based approach}

497 new publications were identified by the search strategy. Of these, 103 were intervention trials and therefore included in the overall analysis; 99 of these were intervention trials using at least one of the 33 treatment modalities identified, 3 were systematic reviews, and 1 was a meta-analysis. The previously identified publications were also reviewed and those that were not exclusively knee OA in the initial analysis were rejected. In total, 545 publications were included. Treatments that are no longer in use (for example, glycosaminoglycan polyscaccharides) were not included in

\begin{tabular}{|c|c|}
\hline Category & Evidence from: \\
\hline $1 \mathrm{~A}$ & Meta-analysis of RCTs \\
\hline BB & At least one RCT \\
\hline $2 \mathrm{~A}$ & At least one controlled study without randomisation \\
\hline $2 \mathrm{~B}$ & At least one quasi-experimental study \\
\hline 3 & $\begin{array}{l}\text { Descriptive studies, such as comparative, } \\
\text { correlation or case-control studies }\end{array}$ \\
\hline 4 & $\begin{array}{l}\text { Expert committee reports or opinions and/ } \\
\text { or clinical experience of respected authorities }\end{array}$ \\
\hline
\end{tabular}

the tabular analysis. Table 4 outlines the different treatment modalities with quality scores and effect sizes where they could be calculated. Table 5 outlines the level of evidence for each and also the strength of recommendation from the expert panel.

A large number of trials examined NSAIDs. 135 NSAID trials were included in this analysis, but only 35 of these had a placebo arm and the ES could only be calculated in five of these. Median quality scores were much higher for the newer coxib trials than for trials investigating conventional NSAIDs.

Quality scores varied enormously for many of the interventions. Those studies conducted more recently tended to be of a higher design quality. Median quality scores were highest for glucosamine and chondroitin sulphate trials and lowest for the surgical trials, tending to parallel the level of evidence found for each modality.

Of the 33 treatment modalities, 29 were supported by evidence from at least one RCT and were graded as either IA or $1 \mathrm{~B}$ for category of evidence. Of the surgical trials, only those assessing arthroscopy \pm debridement were supported by evidence from RCTs.

\section{Toxicity profile}

NSAIDs, opioid analgesics, and psychotropic antidepressant drugs were regarded as having a similar toxicity profile in long term use to that of joint replacement surgery.

When NSAIDs were subdivided into conventional and coxib groups, the results showed that the perceived mean toxicity of non-selective NSAIDs was $51 \mathrm{~mm}$ and the coxib mean $41 \mathrm{~mm}$ on a $100 \mathrm{~mm}$ visual analogue scale.

\section{Experts' opinion approach}

Tables 6 and 7 summarise the final recommendations for management and future research agenda as proposed by the expert committee.

Table 3 Strength of recommendation

\begin{tabular}{ll}
\hline Category & Directly based on: \\
\hline A & $\begin{array}{l}\text { Category } 1 \text { evidence } \\
\text { B }\end{array}$ \\
Category 2 evidence or extrapolated recommendation \\
C & $\begin{array}{l}\text { Category category } 1 \text { evidence } \\
\text { from category } 1 \text { or } 2 \text { evidence }\end{array}$ \\
D & $\begin{array}{l}\text { Category } 4 \text { evidence or extrapolated recommendation } \\
\text { from category } 2 \text { or } 3 \text { evidence }\end{array}$ \\
\hline
\end{tabular}




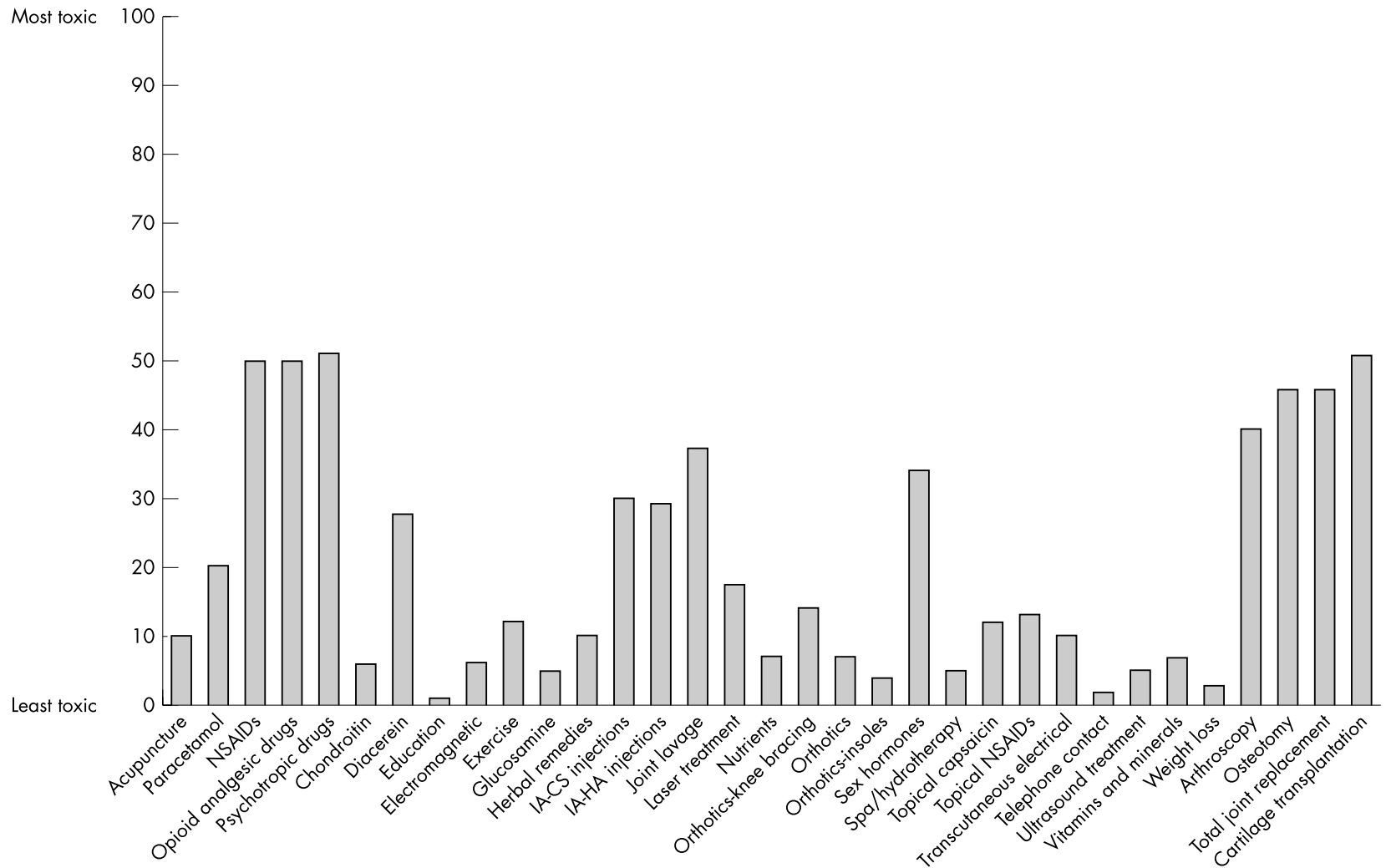

Figure 1 Toxicity profile of the treatment modalities based on expert opinion (23 experts).

\section{Assessment of the propositions}

The propositions are ranked in order of importance as debated by the expert opinion panel.

\section{The optimal management of knee $O A$ requires a combination of non-pharmacological and pharmacological treatment modalities}

Although this statement is logical and represents common clinical practice, there is little direct evidence from appropriately designed factorial RCTs to support this statement. There is, however, a wealth of indirect evidence from RCTs in which all subjects were receiving analgesics or NSAIDs at baseline that non-pharmacological treatments offer additional benefit over and above analgesic or NSAID usage. These have demonstrated that exercise programmes ${ }^{15}$ (quality score (QS) 26), physiotherapy ${ }^{16}$ (QS 26), weight loss combined with exercise $^{17}(\mathrm{QS} 21)$, education ${ }^{18}$ (QS 12), and wedged insoles ${ }^{19}{ }^{20}$ (QS 10, 11) offer additional benefit when used with an analgesic or NSAID regimen. There is therefore a reasonable evidence base to support this statement (1B).

\section{The treatment of knee OA should be tailored according to:}

- Knee risk factors (obesity, adverse mechanical factors, physical activity)

- General risk factors (age, comorbidity, polypharmacy)

- Level of pain intensity and disability

- Sign of inflammation-for example, effusion

- Location and degree of structural damage.

This statement represents ideal practice and includes clinical markers that are often used to guide clinical decisions. Clinical trials predominantly investigate the efficacy of one or two specific monotherapies in highly selected homogeneous populations of otherwise fit subjects with knee OA. These data therefore are not directly applicable to the whole population of subjects with OA. Those studies that have examined the predictors of response to treatment often have limited statistical power, and therefore results are often inconclusive. An example is the presence of an effusion predicting a response to intra-articular steroids where two studies have shown conflicting results ${ }^{21}{ }^{22}$ (QS 22, 17). One RCT involving 84 patients confirmed short term symptom benefit of steroid over placebo and found a better outcome in those with an effusion. However, a randomised crossover study of methylprednisolone versus saline found no clinical predictors of response, suggesting that steroid injection should not be reserved just for those with effusion alone.

As well as the expected relative benefits, potential dangers and costs of the intervention must clearly be taken into account. This has relevance to both medical and surgical interventions. The holistic approach to the patient is universally accepted: it has obvious validity but no research based justification specific to knee OA.

\section{Non-pharmacological treatment of knee OA should include, education, exercise, appliances} (sticks, insoles, knee bracing) and weight reduction Education and provision of information should form an integral part of the management of any chronic disease. This is a professional obligation and should include details of the disease, its investigations, and management. Practitioners should tailor any treatment to the individual needs of the patient and this concept can be discussed within education. Several large RCTs and a meta-analysis have demonstrated the benefits of different educational techniques in reducing pain and increasing coping skills, but with little impact on function in patients with knee $\mathrm{OA}^{23}$ Education has also been shown to result in fewer visits to 
Table 4 Summary of the effect size versus placebo, quality scores, and number of studies identified

\begin{tabular}{|c|c|c|c|c|c|}
\hline Intervention & $\begin{array}{l}\text { Number } \\
\text { of studies }\end{array}$ & $\begin{array}{l}\text { Positive to } \\
\text { placebo }\end{array}$ & $\begin{array}{l}\text { Quality } \\
\text { score } \\
\text { (range) }\end{array}$ & $\begin{array}{l}\text { Quality } \\
\text { score } \\
\text { (median) }\end{array}$ & $\begin{array}{l}\text { Effect size versus } \\
\text { placebo }\end{array}$ \\
\hline Acetaminophen/paracetamol & 5 & $1 / 1$ & $17-26$ & 20 & \\
\hline $\begin{array}{l}\text { Opioid analgesic/other } \\
\text { NSAID }\end{array}$ & 6 & $2 / 3$ & $11-24$ & 19 & \\
\hline Conventional NSAID & 130 & $27 / 31$ & $5-27$ & 17 & $0.47,0.50,0.76,0.96$ \\
\hline Coxibs & 5 & $4 / 4$ & $18-25$ & 23 & 0.50 \\
\hline Antidepressant & 1 & $1 / 0$ & 16 & - & \\
\hline Topical NSAID & 9 & $5 / 7$ & $18-26$ & 22 & $\begin{array}{l}-0.05,0.16,0.31 \\
0.91,1.03\end{array}$ \\
\hline Topical capsaicin & 2 & $2 / 2$ & 21,26 & & $0.41,0.56$ \\
\hline \multirow{2}{*}{\multicolumn{6}{|c|}{$\begin{array}{l}\text { SYSADOA } \\
\text { SYA }\end{array}$}} \\
\hline & & & & & \\
\hline Glucosamine & 8 & $4 / 6$ & $14-27$ & 24 & $0.43,0.53,1.02$ \\
\hline Chondroitin & 5 & $5 / 5$ & $20-27$ & 24 & $1.23,1.37,1.44,1.50$ \\
\hline Diacerein & 1 & $1 / 1$ & 22 & 22 & \\
\hline ASU & 3 & $3 / 3$ & $21-24$ & 23 & $0.32,1.72$ \\
\hline Nutrients & 2 & $2 / 2$ & 4,25 & - & 0.65 \\
\hline Herbal remedies & 5 & $3 / 3$ & $14-27$ & 20 & $0.23,1.32$ \\
\hline Minerals/vitamins & 1 & $0 / 1$ & 24 & 24 & \\
\hline Education & 7 & $3 / 3$ & $11-15$ & 13 & $0.28,0.35$ \\
\hline Exercise & 40 & $8 / 9$ & $5-26$ & 15 & $0.57,0.59,1.0$ \\
\hline Telephone & 3 & $1 / 1$ & $16-18$ & 18 & 1.09 \\
\hline Acupuncture & 6 & $2 / 2$ & $11-22$ & 16 & $0.25,1.74$ \\
\hline Laser & 2 & $1 / 1$ & 12,17 & & 0.87 \\
\hline Pulsed EMF & 2 & $2 / 2$ & 18,19 & & \\
\hline Spa & 5 & $3 / 3$ & $12-17$ & 15 & 1.0 \\
\hline TENS & 7 & $6 / 6$ & $12-22$ & 17 & 0.76 \\
\hline Ultrasound & 1 & $0 / 1$ & 20 & & \\
\hline Weight loss & 2 & $1 / 1$ & 11,15 & & \\
\hline Insoles & 5 & $0 / 1$ & $3-15$ & 11 & \\
\hline $\begin{array}{l}\text { Orthotic device (knee brace/ } \\
\text { patella tape/elastic bandage }\end{array}$ & 9 & $3 / 3$ & $7-20$ & 15 & \\
\hline $\begin{array}{l}\text { IA Hyaluronic acid } \\
\text { Iandage }\end{array}$ & 35 & $18 / 20$ & $9-26$ & 20 & $\begin{array}{l}0.0,0.04,0.48,0.49 \\
0.88,0.9\end{array}$ \\
\hline IA Corticosteroid & 9 & $6 / 7$ & $4-22$ & 16 & 1.27 \\
\hline Lavage/tidal irrigation & 7 & $1 / 1$ & $11-25$ & 18 & 0.84 \\
\hline Arthroscopy & 14 & - & $6-17$ & 10 & \\
\hline Osteotomy & 26 & - & $5-15$ & 11 & \\
\hline $\begin{array}{l}\text { Unicompartmental knee } \\
\text { replacement }\end{array}$ & 15 & - & $4-16$ & 11 & \\
\hline Total knee replacement & 35 & - & $4-23$ & 13 & \\
\hline
\end{tabular}

primary care and therefore also has a cost implication. In a study of 211 patients with knee OA, $80 \%$ of the costs of delivering effective self care education were offset within a year by the reduced frequency and costs of primary care visits. ${ }^{24}$ Education techniques shown to be effective include individualised education packages ${ }^{25}$ (QS 12), regular telephone calls $^{26}$ (QS 17), group education ${ }^{27}(\mathrm{QS} 20)$, patient coping skills ${ }^{28}$ (QS 13), and spouse assisted coping skills training $^{29}$ (QS 15).

There is evidence from large RCTs that joint-specific exercises reduce pain and improve function in patients with knee OA. However, the optimal exercise regimen has not yet been determined. Exercise can be divided into joint-specific strength and range of motion exercises and general aerobic conditioning and can be either directly supervised on land or water or offered as a home based, self directed programme. A two centre RCT of 439 older patients with knee OA demonstrated that the cumulative incidence of disability for activities of daily living was lower in both exercise groups (aerobic exercise and resistance exercise) than in a no-exercise control group ${ }^{30}$ (QS 24). The effectiveness of home exercise on knee OA has been explored in several RCTs, showing reduced pain scores and improved function ${ }^{15} 3132$ (QS 26, 26, 20). Aerobic and isokinetic exercise regimens have also been effective in improving function and gait, and decreasing pain ${ }^{16} 27333^{34}$ (QS 26, 20, 19, 25). No differences were found between a land based exercise programme and an aquatic programme, although both showed significant improvements in pain and function ${ }^{35}$ (QS 17). Importantly, some of these studies report long term improvements (6-18 months). ES for exercise ranged from 0.57 to 1.0

One RCT in 119 patients demonstrated that the pain and function of patients with varus knee OA using a knee brace improved significantly compared with those who did not use a brace ${ }^{36}$ (QS 20). An RCT comparing laterally wedged insoles with neutrally wedged insoles showed no statistical difference between the two groups. However, the group using laterally wedged insoles had a greater reduction in NSAID use together with increased compliance ${ }^{37}(\mathrm{QS}$ 25). Two controlled studies of insoles ${ }^{19} 20$ (QS 10, 11) demonstrated an improvement over an analgesic control group. A study of cross over within subjects suggested that the pain relief and improvement in function reported might be due in part to the reduced external varus moment and medial compartment load short term ${ }^{38}(\mathrm{QS15})$. No RCTs have examined walking sticks or elastic bandage in the management of knee OA. Application of an elastic bandage in 68 patients reduced knee pain significantly in a short term study of cross over within subjects ${ }^{39}$ (QS 20).

Although recommended to virtually all patients with knee OA, the relationship between weight reduction and knee OA has only been assessed formally in two studies. A large cohort study $^{40}$ (QS 15) showed that weight loss reduced the risk of 
Table 5 Level of evidence based on the literature search, and strength of recommendation based on both evidence and expert opinion

\begin{tabular}{|c|c|c|c|}
\hline Intervention & $\begin{array}{l}\text { Level of } \\
\text { evidence }\end{array}$ & $\begin{array}{l}\text { Effect size } \\
\text { Range }\end{array}$ & $\begin{array}{l}\text { Strength of } \\
\text { recommendation }\end{array}$ \\
\hline Acetaminophen/paracetamol & $1 \mathrm{~B}$ & & $A$ \\
\hline Opioid analgesics & $1 \mathrm{~B}$ & & B \\
\hline NSAIDs & & & \\
\hline Conventional NSAID & 1A & $0.47-0.96$ & A \\
\hline Coxibs & $1 B$ & 0.5 & A \\
\hline Antidepressant & 1B & & B \\
\hline Topical NSAID & $1 \mathrm{~A}$ & $-0.05-1.03$ & A \\
\hline Topical capsaicin & $1 \mathrm{~A}$ & $0.41-0.56$ & $A$ \\
\hline Sex hormones & $2 B$ & & C \\
\hline SYSADOA & & & \\
\hline Glucosamine & $1 \mathrm{~A}$ & $0.43-1.02$ & $A$ \\
\hline Chondroitin & $1 \mathrm{~A}$ & $1.23-1.50$ & $A$ \\
\hline Diacerein & $1 \mathrm{~B}$ & & B \\
\hline ASU & $1 B$ & $0.32-1.72$ & B \\
\hline Nutrients & $1 \mathrm{~B}$ & 0.65 & B \\
\hline Herbal remedies & $1 \mathrm{~B}$ & $0.23-1.32$ & B \\
\hline Minerals/vitamins & $1 \mathrm{~B}$ & & $\mathrm{C}$ \\
\hline Education & $1 \mathrm{~A}$ & $0.28-0.35$ & $A$ \\
\hline Exercise & $1 \mathrm{~B}$ & $0.57-1.0$ & A \\
\hline Telephone & $1 \mathrm{~B}$ & 1.09 & B \\
\hline Acupuncture & $1 \mathrm{~B}$ & $0.25-1.74$ & B \\
\hline Laser & $1 \mathrm{~B}$ & 0.87 & B \\
\hline Pulsed EMF & $1 \mathrm{~B}$ & & B \\
\hline Spa therapy & IB & 1.0 & $\mathrm{C}$ \\
\hline TENS & $1 \mathrm{~B}$ & 0.76 & B \\
\hline Ultrasound & $1 \mathrm{~B}$ & & C \\
\hline Weight loss & IB & & B \\
\hline Insoles & $1 \mathrm{~B}$ & & B \\
\hline $\begin{array}{l}\text { Orthotic device (knee brace/ } \\
\text { patella tape/elastic bandage }\end{array}$ & $1 \mathrm{~B}$ & & B \\
\hline A Hyaluronic acid & $1 B$ & $0.0-0.9$ & B \\
\hline IA Corticosteroid & $1 \mathrm{~B}$ & 1.27 & $A$ \\
\hline Lavage/tidal irrigation & $1 B$ & 0.84 & B \\
\hline Arthroscopy \pm debridement & 1B & & C \\
\hline Osteotomy & 3 & & C \\
\hline UCKR & 3 & & C \\
\hline TKR & 3 & & C \\
\hline
\end{tabular}

developing symptomatic knee OA in women. A more recent RCT demonstrated that weight loss combined with exercise reduces pain and improves function in older adults for at least six months; unfortunately, no group had weight loss alone ${ }^{17}$ (QS 21).

In summary, there is good evidence that education (1A) and exercise regimens (IB) reduce pain in knee OA and that exercise regimens also improve function. The use of appliances and weight loss seem sensible options in patients with knee OA, but are only supported by relatively weak evidence, with the exception of knee bracing which has level (1B) evidence for reduction in pain and improvement in function.

4. Paracetamol is the oral analgesic to try first and, if successful, the preferred long term oral analgesic Paracetamol is frequently used as self medication for the treatment of mild to moderate pain. It is the recommended

\footnotetext{
Table 6 Final set of 10 recommendations based on both evidence and expert opinion

\begin{tabular}{ll}
\hline 1 & The optimal management of knee OA requires a combination of non-pharmacological and pharmacological treatment modalities \\
2 & The treatment of knee OA should be tailored according to: \\
(a) Knee risk factors (obesity, adverse mechanical factors, physical activity) \\
(b) General risk factors (age, comorbidity, polypharmacy) \\
(c) Level of pain intensity and disability \\
(d) Sign of inflammation - for example, effusion \\
(e) Location and degree of structural damage \\
Non-pharmacological treatment of knee OA should include regular education, exercise, appliances (sticks, insoles, knee bracing), and \\
weight reduction \\
Paracetamol is the oral analgesic to try first and, if successful, the preferred long term oral analgesic \\
Topical applications (NSAID, capsaicin) have clinical efficacy and are safe \\
NSAIDs should be considered in patients unresponsive to paracetamol. In patients with an increased gastrointestinal risk, non-selective \\
NSAIDs and effective gastroprotective agents, or selective COX 2 inhibitors should be used \\
Opioid analgesics, with or without paracetamol, are useful alternatives in patients in whom NSAIDs, including COX 2 selective \\
inhibitors, are contraindicated, ineffective, and/or poorly tolerated \\
SYSADOA (glucosamine sulphate, chondroitin sulphate, ASU, diacerein, hyaluronic acid) have symptomatic effects and may modify \\
structure \\
Intra-articular injection of long acting corticosteroid is indicated for flare of knee pain, especially if accompanied by effusion \\
Joint replacement has to be considered in patients with radiographic evidence of knee OA who have refractory pain and disability \\
\hline
\end{tabular}
}


Table 7 Research agenda based on expert opinion

\begin{tabular}{ll}
\hline 1 & Clinical predictors of response to pharmacological and non-pharmacological interventions need to be determined \\
2 & There is a need to establish a set of recommendations for uniform and full reporting of clinical trials in knee OA \\
3 & Studies should include quality of life and function as well as pain, as outcome measures \\
4 & New imagining techniques - that is, MRI and ultrasound require validation for the diagnosis and follow up of knee OA \\
5 & Randomised controlled trials should more fully assess non-pharmacological interventions for knee OA \\
6 & The most efficient and effective exercises need to be determined \\
7 & What is the effect on tissue, efficacy, and safety of long term COX 2 inhibition \\
8 & The clinical relevance of structural modification requires evaluation \\
9 & The indications for joint replacement need to be determined \\
10 & There is a need to examine the efficacy and cost utility of surgical techniques
\end{tabular}

initial oral analgesic for knee OA in published guidelines (ACR, RCP, EULAR). However, few studies have directly assessed the efficacy of paracetamol in knee OA and those that have are either of poor quality or have small patient numbers. A six week RCT in just 25 patients $^{41}$ (QS 21) showed a significant improvement in pain at rest with paracetamol compared with placebo. One four week RCT showed that paracetamol $4 \mathrm{~g} /$ day was as effective as ibuprofen (up to $2400 \mathrm{mg} / \mathrm{day})^{42}$ (QS 26). Re-evaluation of these data demonstrated that even severe knee pain responded equally to paracetamol and ibuprofen ${ }^{43}$ (QS 17). Another RCT showed that paracetamol could be used effectively in doses of up to $2600 \mathrm{mg} /$ day for two years without significant adverse outcomes; it also showed that the efficacy of paracetamol was similar to that of naproxen $750 \mathrm{mg} /$ day. This study had a high rate of withdrawals in both treatment arms, and the authors suggested that neither drug was satisfactory for the treatment of $\mathrm{OA}^{44}(\mathrm{QS} 23)$. The issue of efficacy is clouded by the fact that most RCTs use paracetamol as escape analgesia, converting monotherapy trials to partial adjunctive studies. There are few drug interactions and no common contraindications to the use of paracetamol, including in the elderly.

In summary, there is evidence (1B) that paracetamol is effective in the treatment of knee OA and that in many patients it is comparable with ibuprofen in the short term and almost as efficacious as naproxen. There is also evidence (1B) that paracetamol can be taken safely over the long term. Clearly, a drug that is both safe and commonly effective should be considered early in the management of knee OA and, if effective, as an integral component of long term pain control.

There has been much recent controversy about the gastrointestinal safety of paracetamol, particularly as compared with NSAIDs. A recent editorial covers this issue well, with a review of the current available literature. ${ }^{45}$ It concludes that currently the weight of clinical evidence supports the better overall gastrointestinal safety profile of paracetamol compared with non-selective NSAIDs.

\section{Topical applications (NSAID, capsaicin) have clinical efficacy and are safe}

Topical agents are commonly used, well tolerated and liked by patients. Two RCTs comparing topical diclofenac with placebo, in 70 and 155 patients respectively, recorded significant benefit over placebo for pain $\operatorname{relief}^{46}{ }^{47}$ (QS 24, 22). Interestingly, two RCTs comparing eltenac gel with placebo, involving 290 and 237 patients respectively, showed a significant improvement in pain relief only in those with severe knee $\mathrm{OA}^{48}{ }^{49}$ (QS 26, 25). Studies comparing diclofenac gel with ketoprofen gel $^{50}(\mathrm{QS}$ 19) and piroxicam gel with oral ibuprofen $^{51}$ (QS 20) showed equal efficacy between treatments. The ES for this form of treatment varies widely with a median ES of 0.31 (range -0.05 to 1.03 ). Topical NSAIDs have a good safety record. Large surveillance studies in general practice ${ }^{52}$ suggest good safety (adverse events $<1.5 \%$ ) with local skin reactions the principal side effect, and one large case-control study has found no association between topical NSAIDs and upper gastrointestinal bleeding or perforation. $^{53}$

Topical capsaicin (a treatment which reversibly desensitises nociceptive $\mathrm{C}$ fibres by acting on the VR- $\mathrm{l}$ vaniloid receptors) is increasingly used in OA. There is good evidence for its efficacy in knee OA from an RCT, and it would appear its efficacy is maintained ${ }^{54}$ (QS 21). ES ranges from 0.41 to 0.56 . No systemic side effects are reported.

There is (1B) evidence for the efficacy and use of topical NSAIDs and capsaicin in the management of knee OA and these treatments have a good safety record.

\section{NSAIDs should be considered in patients unresponsive to paracetamol. In patients with an increased gastrointestinal risk, non-selective NSAIDs and effective gastroprotective agents, or selective COX 2 inhibitors should be used}

There is good evidence that NSAIDs are more efficacious than paracetamol for some patients, but the statement that they should be used in patients in whom paracetamol has failed, although attractive, does not have an evidence base. Unfortunately, there are no trials using failure of pain relief when treated with paracetamol as entry criteria for the trial.

With increasing focus on the low grade inflammatory component of OA, NSAIDs would appear to be logical drugs in patients unresponsive to paracetamol, particularly in the presence of clinically overt synovitis. However, there is no direct evidence base to support this statement. Numerous studies have shown that oral NSAIDs are better than placebo (ES median 0.50, range 0.47-0.96), confirming the efficacy of NSAIDs in the management of knee OA. A Cochrane review examining the relative efficacy of different NSAIDs used in knee OA concluded that despite the large number of publications in this area, many trials were poorly designed, and there was no evidence to distinguish between the efficacy of equivalent recommended doses of conventional NSAIDs. ${ }^{55}$

A few trials have directly compared paracetamol and NSAIDs. They have generally, but not exclusively, found that NSAIDs have better efficacy but increased gastrointestinal side effects. In a two year $\mathrm{RCT}^{44}$ (QS 23) paracetamol was compared with naproxen in 178 patients. Naproxen led to greater reductions in pain than paracetamol (ES 0.32 after 42 days and 0.45 after 730 days). Patient drop out was high (65\%) owing to lack of efficacy in the paracetamol arm and to adverse events in the naproxen arm. A further trial of 382 patients comparing rofecoxib, celecoxib, and paracetamol demonstrated that more patients discontinued treatment early with paracetamol because of lack of efficacy and that significantly more pain relief was obtained with the coxibs than with paracetamol; side effect profiles were similar for all treatment $\operatorname{arms}^{56}(\mathrm{QS} 23)$. 
There has been speculation that COX 2 selective agents are more beneficial than conventional NSAIDs, particularly in those at higher risk of adverse gastrointestinal side effects. Large trials comparing COX 2 inhibitors with placebo and conventional NSAIDs have shown their superiority over placebo and a similar efficacy to conventional NSAIDs for pain relief but with a reduction-up to $50 \%$-in perforation, ulcers, and bleeding. An RCT comparing celecoxib, diclofenac, and placebo in 600 patients over six weeks showed that both drugs were better than placebo in improving pain but showed no difference between active treatments. There were more gastrointestinal side effects with diclofenac than celecoxib and the coxib was better tolerated ${ }^{57}$ (QS21); there was an ES of 0.5 in comparison with placebo. A further study comparing varying doses of celecoxib with naproxen and placebo in 1003 patients found equal efficacy between the active treatment groups compared with placebo and an increased drop out rate in the placebo group due to lack of efficacy; in this study, however, the incidence of minor gastrointestinal related adverse events was similar for conventional NSAIDs and coxib, but one case of acute gastrointestinal bleeding occurred in the naproxen group $^{58}(\mathrm{QS25})$. Current reports show that cardiorenal adverse events occur equally in patients treated with non-selective NSAIDs and coxibs.

A recent Cochrane review, including publications up to July 2002, examined the effectiveness of interventions for the prevention of NSAID induced upper gastrointestinal toxicity. ${ }^{59}$ This included 40 RCTs and concluded that all doses of misoprostol significantly reduced the risk of endoscopic ulcers. Standard doses of histamine-2 receptor antagonists effectively reduced the risk of endoscopic duodenal but not gastric ulcers. Double doses of histamine-2 receptor antagonists and protein pump inhibitors effectively reduced the risk of endoscopic duodenal and gastric ulcers, and were better tolerated than misoprostol.

There is therefore (1A) evidence to support the use of NSAIDs in the treatment of knee OA. In those with an increased risk of gastrointestinal complications the evidence supports the use of either a COX 2 selective agent or the addition of a gastroprotective agent to a conventional NSAID.

\section{Opioid analgesics, with or without paracetamol, are useful alternatives in patients in whom NSAIDs, including COX 2 selective inhibitors, are contraindicated, ineffective, and/or poorly tolerated}

There is little direct evidence to fully support this statement. However, there is indirect evidence and the use of opioid analgesics is widely accepted in everyday clinical practice when other therapeutic options are limited. Indirect evidence would support that there is increased efficacy of pain control in those patients not entirely responsive to paracetamol and/ or NSAIDs. It would be prudent, however, to counsel on the increased risk of adverse side effects, particularly in the elderly, and potential dependence when using this group of drugs. An RCT of 90 patients showed that treatment of knee OA with tramadol allowed reduction of the naproxen dose among those patients with naproxen-responsive pain ${ }^{60}$ (QS 19). There is therefore (1B) evidence to support this statement.

\section{SYSADOA (glucosamine sulphate, chondroitin sulphate, ASU, diacerein, and hyaluronic acid) have symptomatic effects and may modify structure} SYSADOA is a generic term used for symptomatic slow acting drugs for OA, and includes glucosamine sulphate and related compounds, chondroitin sulphate, and diacerein. There is wide variability throughout Europe in the use of these drugs and how they are classified. In the United Kingdom, for instance, they are classified as a health food supplement rather than a prescribable drug, are available only over the counter, and are very widely self administered. Those SYSADOA (for example, glycosaminoglycan polysulphates) that are no longer in use throughout Europe have not been included in this analysis. The other products have been assessed individually.

Both chondroitin sulphate and glucosamine sulphate have been the focus of a meta-analysis, including all studies up to 1999. ${ }^{61}$ This report concluded that trials of chondroitin and glucosamine compounds demonstrated moderate to large effects on pain and disability in OA compared with placebo; however, these effects may have been exaggerated by publication bias. These products are also safe and associated with few side effects. The ES calculated for chondroitin sulphate was 0.78 and for glucosamine 0.44 in this metaanalysis, where they combined all the studies.

In an RCT assessing the efficacy of chondroitin sulphate compared with diclofenac in 146 patients, a prompter reduction of clinical symptoms was seen in patients treated with the NSAID, but these returned after the end of treatment; chondroitin, however, had a slower onset of action on the therapeutic response, but this lasted for up to three months after the end of treatment ${ }^{62}$ (QS20). A more recent $\mathrm{RCT}^{63}$ (QS 27) demonstrated the benefit of chondroitin over placebo in 130 patients with knee OA and again showed persisting efficacy for up to one month after treatment.

Two RCTs have compared the effect of glucosamine sulphate with ibuprofen. The first, conducted over an eight week period, showed that ibuprofen was more effective at decreasing pain scores within the first two weeks of treatment, but at eight weeks, glucosamine sulphate was significantly better ${ }^{64}$ (QS 22). The second, conducted over four weeks, demonstrated that ibuprofen had a faster onset of action, but at four weeks the pain reduction and disability were $\operatorname{similar}^{65}$ (QS 23). Two other placebo controlled RCTs have been published in addition to those assessed in the meta-analysis. Ninety eight older patients with moderate to severe knee OA showed no difference in pain or function with glucosamine sulphate compared with placebo over a two month period $^{66}$ (QS 24). However, 106 patients with mild to moderate knee OA showed delayed progression of joint space loss and improvement in pain and function scores as compared with placebo over a three year period ${ }^{67}(\mathrm{QS} 26)$. This had led to the suggestion that glucosamine sulphate could be used as a structure modifying agent in knee OA. Only one RCT has examined the efficacy of glucosamine and chondroitin sulphate in combination; in 93 patients, those with mild to moderate knee OA had significant improvement in the Lequesne index of knee severity score at four and six months; those with severe disease had no improvement over placebo $^{68}$ (QS 24). An ES of 0.53-0.87 was calculated for glucosamine sulphate, excluding those used in the metaanalysis.

Only one RCT of diacerein in patients with knee OA was identified. At doses of $100 \mathrm{mg}$ daily, significant differences in pain and handicap scores were seen compared with placebo. At higher doses, a significant number of adverse events were $\operatorname{seen}^{69}($ QS 22).

The introduction of hyaluronic acid (HA) has been viewed as an advance in the management of knee OA. Its role in pain reduction, functional improvement, and in disease modification in knee OA has been assessed. Several HA preparations exist, in two main categories: high molecular and low molecular weight. It has been postulated that those preparations with a high molecular weight may have a superior effect. A 12 week RCT comparing a high molecular HA with a 
low molecular HA showed that the higher molecular weight product was significantly better in relieving pain ${ }^{70}$ (QS 21). Until February 2002, 39 trials have assessed the efficacy of HA for knee OA. Twenty trials assessed HA versus placebo and 18 of these were positive. RCTs that allowed calculation of ES recorded significant reductions in pain against placebo (ES $0.04,0.49,0.88,0.9$ ) over periods of 60 days to one year ${ }^{71-74}$ (QS 22,19,23,14). One study recorded functional improvements on the Lequesne index (ES 0.36) over one year. $^{70}$

Few trials have directly examined the effect on structure modification. One RCT looked at arthroscopic changes at baseline and after one year; less deterioration was seen over one year when treated with HA, and the HA group also scored higher for quality of life and reduced NSAID use during the period of study. ${ }^{75}$ Another study demonstrated a reduction in the need for intra-articular steroid injections over a one year follow up period; the authors suggested a possible structure modifying effect by reducing flares. ${ }^{71}$

Studies examining possible predictors of response are few. Patients over 60 years with important functional impairment as documented by the Lesquesne index were associated with the greater efficacy of $\mathrm{HA}$ in one $\operatorname{study}^{76}(\mathrm{QS} 26)$. A retrospective study found that the response to HA was statistically influenced by structural severity of the knee OA-those with less severe disease did better, and those with an effusion at baseline did worse $^{77}(\mathrm{QS}$ 18). It is noteworthy that most trials investigating intra-articular HA exclude severe OA.

In summary, there is evidence to support the efficacy of HA in the management of knee OA both for pain reduction (1B) and functional improvement (1B). However, although pain relief may be obtained for several months, rather than for several weeks as with steroid, this benefit may be offset by its slower onset of action and by the requirement of a course of 3-5 weekly injections with the logistical and cost issues that that entails. There is minimal evidence for a role in disease modification. The term SYSADOA covers a range of agents. There is growing evidence to support the use of two of these agents for their symptomatic effects-namely, glucosamine sulphate (1A) and chondroitin sulphate (1A), but for the others the evidence is weak or absent.

\section{Intra-articular injection of long acting corticosteroid is indicated for flare of knee pain, especially if accompanied by effusion}

Intra-articular corticosteroid injections in knee OA have been used to relieve pain and inflammation for many years. The effects of steroids in knee OA have been assessed in a number of studies. One RCT concluded that steroid was more effective than placebo for pain relief over seven days (ES 1.27) in patients with knee OA, not all of whom had effusions ${ }^{78}$ (QS 19). Another RCT involving 98 patients showed a significant difference in pain relief and functional outcomes between intra-articular steroid and placebo after one and four weeks but no difference at 12 and 24 weeks $^{79}$ (QS 24). One RCT involving 84 patients confirmed short term symptom benefit of steroid over placebo and found a better outcome in those with an effusion ${ }^{21}$ (QS 22). However, a randomised crossover study of methylprednisolone versus saline found no clinical predictors of response, suggesting that steroid injection should not be reserved just for those with effusion alone ${ }^{22}(17)$.

In conclusion there is evidence (1B) that intra-articular injections of corticosteroid are effective but give relatively short lived benefit. The evidence for predictors of response, however, remains unclear and further studies are needed to answer this question.
10. Joint replacement has to be considered in patients with radiographic evidence of knee OA who have refractory pain and disability

Joint replacement is an irreversible intervention used in those for whom other treatment modalities have failed and who generally have more severe disease. The effectiveness of total knee replacement (TKR) in knee OA has a well established place in those severely incapacitated. A systematic review concluded that TKR was a safe and effective treatment in improving quality of life, ${ }^{80}$ as well as reducing pain and improving function. The evidence base to support this statement is built wholly on class 3 evidence from observational and retrospective analyses, often using prosthesis survival as the primary outcome measure.

A detailed review of surgery for knee OA identified 154 studies of 37 different tricompartmental prostheses in 9879 people $\left(63 \%\right.$ with osteoarthritis OA). ${ }^{81}$ Good or excellent outcomes for pain and function were reported in $89 \%$ of people up to five years after surgery. Unicompartmental and bicompartmental prostheses were also reviewed and showed similar findings. The review concluded that all forms of knee replacement improve quality of life.

The general consensus among orthopaedic surgeons on indications for an operative procedure, carried out by a postal survey, were $(a)$ severe daily pain and $(b) x$ ray evidence of joint space narrowing. ${ }^{82}$ There are no evidence based guidelines to support this, however.

No RCTs have compared TKR with non-surgical interventions. Although it is acknowledged that difficulties with study design may limit randomised studies on surgical treatments, there are areas that should be explored, including predictors of response, indications for joint replacement, and the effect of differences in surgical technique or joint prosthesis on long term outcomes. Moreover, postoperative outcome assessment should be carried out by an investigator independent of the surgeon who has performed the operation.

\section{DISCUSSION}

These clinical recommendations are based on the updated evidence obtained by reviewing the literature up to and including February 2002. The publication also seeks to accommodate all commonly used treatment modalities used in knee OA. The data collected and provided are restricted to the knee only, therefore, and those papers in which summary statistics could not be dissected from the other non-knee data were excluded. Equally, current recommendations cannot be extrapolated to OA at other sites.

The main purpose of the paper is to act as a resource document for secondary care, with the aim that each individual country should use the information generated to produce their own set of management guidelines and algorithms for treatment in primary care. As noted in the 2000 recommendations, there is often discordance between expert opinion and trial evidence, confirming that our own experience and local situations are important in determining individual treatment selection.

Reviewing the literature has reinforced the need to investigate predictors of response to individual treatments as the information relating to this important aspect is limited. Also, there is a lack of information about pooled/combination treatments, which would reflect everyday clinical practice. We still remain ignorant about the difference between efficacy (trial data) and clinical effectiveness (how useful in practice) for many of these treatments.

A heterogeneous array of outcome measures was used which makes comparison between different publications using the same treatment difficult. A more standardised 
way of assessing the various treatments needs to be adopted internationally.

The task force attempted to review the evidence for efficacy of individual treatments and to give an additional more subjective summary of expert opinion on the overall safety and usefulness. The task force made no attempt to design a more didactic algorithm for management, even though it was realised that such a simplistic approach might have more immediate impact on the behaviour of health professionals. Many patient centred factors are important in determining the selection of treatments for individual patients with knee OA-for example, psychosocial factors and OA status; comorbid disease and drugs; patient beliefs about their knee $\mathrm{OA}$; patient beliefs and preferences for its management; and previous patient experiences of treatments and health professionals. The costs and logistics of delivering specific interventions (for example, physiotherapy, weekly knee injections of HA) are also important. Therefore the management plan for patients with knee OA has to be individualised, reviewed, and adjusted in the light of the patient's response and adherence and will vary between patients and between locations. Optimistically, however, the findings of the current EULAR Recommendations show that there is a wide variety of treatments from which to choose for people with knee OA. There is no single right and wrong approach and each health professional must decide with each patient the most appropriate management plan at a particular time and for that location. It is hoped that discussion within healthcare provider groups of the treatment options outlined in this document will improve knowledge and interest in the management of knee OA and result in higher standards of care.

\section{ACKNOWLEDGEMENTS}

We thank Bristol Myers Squibb and, in particular, Dr Manuela Le Bars, for financial and logistical support.

\section{MEMBERS OF TASK FORCE}

Nigel Arden, Southampton General Hospital, Southampton S016 6YD, UK

Bernard Bannwarth, Laboratoire de Thérapeutique, Université Bordeaux II, 33076 Bordeaux Cedex, France

Johannes Bijlsma, Department of Rheumatology and Immunology, University Hospital Utrecht, 3508 Utrecht GA, The Netherlands Paul Dieppe, MRC Health Services Research Collaboration, University of Bristol, Canynghe Hall, Whiteladies Road, Bristol BS8 2PR, UK Michael Doherty, Rheumatology Unit R.U.G., City Hospital, Nottingham NG5 1PB, UK

Maxime Dougados, Service de Rheumatologie B, Hôpital Cochin 75014 Paris, France

Klaus-Peter Gunther, Department of Orthopaedic Surgery, University of Dresden, D-Dresden, Germany

Hans Hauselmann, Centre for Rheumatology and Bone Disease, Clinic Im Park, Hirslanden Group, Bellariast. 38, CH 8038 Zurich, Switzerland

Gabriel Herrero-Beaumont, Rheumatology Department, Clinique de la Conception, 28040 Madrid, Spain

Kelsey Jordan, Florence Cottage, 17 Dover Street, Southampton SOl46GG, UK

Phaedon Kaklamanis, 16 Anaperon Polemon, 11521 Athens, Greece Burkhard Leeb, NÖ Zentrum für Rheumatology, Stockerau Hospital, A-2000 Stockerau, Austria

Michel Lequesne, 31-33 rue Guillemot, 75014 Paris, France

Stefan Lohmander, Deparment of Orthopaedics, University Hospital, S-22185 Lund, Sweden

Bernard Mazieres, Service de Rhumatologie, l avenue Jean Poulhès, CHU Rangueil, 31054 O, Cedex France

Emilio Martin-Mola, Divisione di Reumatologia, Hosptial La Paz, 28046 Madrid, Spain

Karel Pavelka, Institute of Rheumatology, 12850 Praha 2, Czech Republic

Adrian Pendleton, 9 Prince Edward Drive, Stranmillis, Belfast BT9 5GB, Northern Ireland
Leonardo Punzi, Universita degli studi di Padova, Policlinico Universitario - VIII Piano, Via Giustiniani, 2, 35128 Padova, Italy Umberto Serni, Divisione di Reumatologia, Istituto Ortopedico Toscano, Florence, Italy

Berndt Swoboda, Ortopedik Poliklinik der Universität ErlangenNuremberg, D-91054 Erlangen, Germany

Gust Verbruggen, Rheumatology Unit, U.Z R.U.G., B-7000 Gent, Belgium

Irena Zimmermann-Gorska, Department of Rheumatology and Rehabilitation, Karol Marcinkowski University of Medical Sciences, 28 Czerwca 1956r, 135/147, 61-545 Poznan, Poland

\section{REFERENCES}

1 Peat G, McCarney R, Croft P. Knee pain and osteoarthritis in older adults: a review of community burden and current use of health care. Ann Rheum Dis $2001 ; 60: 91-7$

2 Guccione AA, Felson DT, Anderson JJ, Anthony JM, Zhang Y, Wilson PW, et al. The effects of specific medical conditions on the functional limitations of elders in the Framingham study. Am J Publ Health 1994;84:351-8.

3 Murray CJL, Lopez AD. The global burden of disease. Geneva: World Health Organisation, 1997.

4 Cooper C. Epidemiology of osteoarthritis. In: Klippel JH, Dieppe PA, eds. Rheumatology, 2nd ed. London: Mosby, 1998:1-20.

5 Dieppe P, Basler HD, Chard J, Croft P, Dixon J, Hurley M, et al. Knee replacement surgery for osteoarthritis: effectiveness, practice variations, indications and possible determinants of utilisation. Rheumatology (Oxford) 1999;38:73-83.

6 Felson DT. Osteoarthritis new insights. Part 1: the disease and its risk factors. Ann Intern Med 2000; 133:637-9.

7 Cooper C, Snow S, McAlindon TE, Kellingray S, Stuart B, Coggon D, et al. Risk factors for the incidence and progression of radiographic knee osteoarthritis. Arthritis Rheum 2000;43:995-1000.

8 Spector TD, Cicuttini F, Baker J, Loughlin J, Hart D. Genetic influences in women: a twin study. BMJ 1996;312:940-3.

9 Scott DL. Guidelines for the diagnosis, investigation and management of osteoarthritis of the hip and knee. Report of a Joint Working Group of the British Society for Rheumatology and the Research Unit of the Royal College of Physicians. J R Coll Physicians Lond 1993;27:391-6.

10 American College of Rheumatology subcommittee on osteoarthritis guidelines. Recommendations for the medical management of osteoarthritis of the hip and knee. Arthritis Rheum 2000;43:1905-15.

11 Pendlleton A, Arden N, Dougados M, Doherty M, Bannwarth B, Bij|sma JW, et al. EULAR recommendations for the management of knee osteoarthritis: report of a task force of the Standing Committee for International Clinical Studies Including Therapeutic Trials (ESCISIT). Ann Rheum Dis 2000;59:936-44

12 Downs SH, Black N. The feasibility of creating a checklist for the assessment of the methodological quality both of randomised and non-randomised studies of health care interventions. J Epidemiol Community Health 1998;52:377-84.

13 Schwarzer R. Meta-analysis programs version 5.0 Berlin, Germany: Ralf Schwarzer Computer Programs for Meta-Analysis 2000 ( www.fuberlin.de) gesund/meta_e.htm).

14 Cohen J. Statistical power analysis for the behavioural sciences. New York: Academic Press, 1977.

15 Petrella RJ, Bartha C. Home based exercise therapy for older patients with knee osteoarthritis: a randomised controlled trial. J Rheumatol 2000;27:2215-21.

16 Deyle GD, Henderson NE, Matekel RL, Ryder MG, Garber MB, Allison S. Effectiveness of manual physical therapy and exercise in osteoarthritis of the knee: a randomised controlled trial. Ann Intern Med 2000;132:173-81.

17 Messier SP, Loeser RF, Mitchell MN, Valle G, Morgan TP, Rejeski WJ, et al. Exercise and weight loss in obese older adults with knee osteoarthritis: a preliminary study. J Am Geriatr Soc 2000;48:1062-72.

18 Mazzuca SA, Brandt KD, Katz BP, Chambers M, Byrd D, Hanna M. Effects of self-care education on the health status of inner-city patients with osteoarthritis of the knee [see comments]. Arthritis Rheum 1997;40:1466-74.

19 Tohyama H, Yasuda K, Kaneda K. Treatment of osteoarthritis of the knee with heel wedges. Int Orthop 1991;15:31-3.

20 Sasaki T, Yasuda K. Clinical evaluation of the treatment of osteoarthritic knees using a newly designed wedged insole. Clin Orthop 1985;221:181-7.

21 Gaffney VK, Ledingham J, Perry JD. Intra-articular triamcinolone hexacetonide in knee osteoarthritis: factors influencing the clinical response. Ann Rheum Dis 1995:54:379-81.

22 Jones A Doherty M. Intra-articular corticosteroids are effective in osteoarthritis but there are no clinical predictors of response. Ann Rheum Dis 1996;55:829-32

23 Superio-Cabuslay E, Ward MM, Lorig KR. Patient education interventions in osteoarthritis and rheumatoid arthritis: a meta-analytic comparison with nonsteroidal antiinflammatory drug treatment. Arthritis Care Res 1996;9:292-301

24 Mazzuca SA, Brandt KD, Katz BP, Hanna MP, Melfi CA. Reduced utilisation and cost of primary care clinic visits resulting from self-care education for patients with osteoarthritis of the knee. Arthritis Rheum 1999;42:1267-73.

25 Mazzuca SA, Brandt KD, Katz BP, Chambers M, Byrd D, Hanna M. Effects of self-care education on the health status of inner-city patients with osteoarthritis of the knee [see comments]. Arthritis Rheum 1997;40:1466-74. 
26 Weinberger M, Tierney WM, Booher P, Katz BP. Can the provision of information to patients with osteoarthritis improve functional status? A randomised, controlled trial. Arthritis Rheum 1989;32:1577-83.

27 Maurer BT, Stern AG, Kinossian B, Cook KD, Schumacher HR Jr. Osteoarthritis of the knee: isokinetic quadriceps exercise versus an educational intervention. Arch Phys Med Rehabil 1999;80:1293-9.

28 Keefe FJ, Caldwell DS, Williams DA, Gil KM, Mitchell D, Robertson C, et al. Pain coping skills training in the management of osteoarthritic knee pain-II: follow-up results. Behavior Therapy 1990;21:435-47.

29 Keefe FJ, Caldwell DS, Baucom D, Salley A, Robinson E, Timmons K, et al. Spouse-assisted coping skills training in the management of knee pain in osteoarthritis: long-term followup results. Arthritis Care Res 1999;12:101-11.

30 Penninx BWJH, Messier SP, Rejeski WJ, Williamson JD, DiBari M Cavazzini $C$, et al. Physical exercise and the prevention of disability in activities of daily living in older persons with osteoarthritis. Arch Intern Med 2001; 161:2309-16.

31 Baker KR, Nelson ME, Felson DT, Layne JE, Sarno R, Roubenoff R, et al. The efficacy of home based progressive strength training in older adults with knee osteoarthritis: A randomised controlled trial. J Rheumatol 2001;28:1655-65.

32 O'Reilly SC, Muir KR, Doherty M. Effectiveness of home exercise on pain and disability from osteoarthritis of the knee: a randomised controlled trial. Ann Rheum Dis 1999;58:15-19.

33 Mangione KK, McCully K, Gloviak A, Lefebvre I, Hofmann M, Craik R. The effects of high-intensity and low intensity cycle ergometry in older adults with knee osteoarthritis. J Gerontol A Biol Sci Med Sci 1999:54:M184-90.

34 Fransen $M$, Crosbie J, Edmonds J. Physical therapy is effective for patients with osteoarthritis of the knee: a randomised controlled clinical trial. J Rheumatol 2001;28:156-64.

35 Wyatt FB, Milam S, Manske RC, Deere R. The effects of aquatic and traditional exercise programs on persons with knee osteoarthritis. J Strength Cond Res $2001 ; 15: 337-40$

36 Kirkley A, Webster-Bogaert S, Litchfield R, Amendola A, MacDonald S, McCalden $R$, et al. The effect of bracing on varus gonarthrosis. J Bone Joint Surg Am 1999:81:539-48.

37 Maillefert JF, Hudry C, Baron G, Kieffert P, Bourgeois P, Lechavalier D, et al. Laterally elevated wedged insoles in the treatment of medial knee osteoarthritis: a prospective randomized controlled study. Osteoarthritis Cartilage 2001;9:738-45.

38 Crenshaw SJ, Pollo FE, Calton EF. Effects of lateral wedged insoles on kinetics at the knee. Clin Orthop 2000;375:185-92.

39 Hassan BS, Mockett S, Doherty M. Influence of elastic bandage on knee pain, proprioception, and postural sway in subjects with knee osteoarthritis. Ann Rheum Dis 2002;61:24-8.

40 Felson DT, Zhang Y, Anthony JM, Naimark A, Anderson JJ. Weight loss reduces the risk for symptomatic knee osteoarthritis in women. The Framingham Study. Ann Intern Med 1992;116:535-9.

41 Amadio P, Cummings DM. Evaluation of acetaminophen in the management of osteoarthritis of the knee. Cur Ther Res 1983;34:59-66.

42 Bradley JD, Brandt KD, Katz BP, Kalasinski LA, Ryan SI. Treatment of knee osteoarthritis: relationship of clinical features of joint inflammation to the response to a nonsteroidal antiinflammatory drug or pure analgesic. J Rheumatol 1992;19:1950-4.

43 Bradley JD, Katz BP, Brandt KD. Severity of knee pain does not predict a better response to an antiinflammatory dose of ibuprofen than to analgesic therapy in patients with osteoarthritis. J Rheumatol 2001;28:1073-6.

44 Williams HJ, Ward JR, Egger MJ, Neuner R, Brooks RH, Clegg DO, et al. Comparison of naproxen and acetaminophen in a two-year study of treatment of osteoarthritis of the knee. Arthritis Rheum 1993;36:1196-206.

45 Abramson SA. Et tu acetaminophen? Arthritis Rheum 2002;46:2831-5.

46 Grace D, Rogers J, Skeith K, Anderson K. Topical diclofenac versus placebo: a double blind, randomised clinical trial in patients with osteoarthritis of the knee. J Rheumatol 1999;26:2659-63.

47 Dreiser RL, Tisne-Camus M. DHEP plasters as a topical treatment of knee osteoarthritis-a double blind placebo-controlled study. Drugs Exp Clin Res 1993; 19:121-7.

48 Sandelin J, Harilainen A, Crone H, Hamberg P, Forsskahl B, Tamelander G. Local NSAID gel (eltenac) in the treatment of osteoarthritis of the knee. A double blind study comparing eltenac with oral diclofenac and placebo gel. Scand J Rheumatol 1997:26:287-92

49 Ottilinger B, Gomor B, Michel BA, Pavelka K, Beck W, Elsasser U. Efficacy and safety of eltenac gel in the treatment of knee osteoarthritis. Osteoarthritis Cartilage 2001:9:273-80

50 Waikakul S, Penkitti P, Soparat K, Boonsanong W. Topical analgesics for knee arthrosis: a parallel study of ketoprofen gel and diclofenac gel. J Med Assoc Thai 1997;80:593-7.

51 Dickson DJ. A double blind evaluation of topical piroxicam gel with oral ibuprofen in osteoarthritis of the knee. Curr Ther Res 1991:49:199-207.

52 Newbery R, Shuttleworth P, Rapier C. A multicentre post marketing surveillance study to evaluate the safety and efficacy of felbinac $3 \%$ gel in the treatment of musculoskeletal disorders in general practice. Eur $J$ Clin Res 1992:3:139-50.

53 Evans JMM, McMahon AD, McGilchrist MM, White G, Murray FE, McDevitt DG, et al. Topical non-steroidal anti-inflammatory drugs and admission to hospital for upper gastrointestinal bleeding and perforation: a record linkage case control study. BMJ 1995:311:22-6.

54 Deal CL, Schnitzer TJ, Lipstein E, eibold JR, Stevens RM, Levy MD, et al. Treatment of arthritis with topical capsaicin: a double-blind trial. Clin Ther $1991 ; 13: 383-95$
55 Watson MC, Brookes ST, Kirwan JR, Faulkner A. Non-aspirin, non-steroidal anti-inflammatory drugs for treating osteoarthritis of the knee (Cochrane review). In: The Cochrane Library, Issue 1. Oxford: Update Software, 2002.

56 Geba GP, Weaver AL, Polis AB, Dixon ME, Schnitzer TJ. Efficacy of rofecoxib, celecoxib, and acetaminophen in osteoarthritis of the knee. JAMA 2002;287:64-71

57 McKenna F, Borenstein D, Wendt H, Wallemark C, Lefkowith JB, Geis GS. Celecoxib versus diclofenac in the management of osteoarthritis of the knee. Scand J Rheumatol 2001;30:11-18.

58 Bensen WG, Fiechtner JJ, McMillen Jl, Zhao WW, Yu SS, Woods EM, et al. Treatment of osteoarthritis with celecoxib, a cyclo-oxygenase-2 inhibitor: a randomised controlled trial. Mayo Clin Proc 1999;74:1095-105.

59 Rostom A, Dube C, Wells G, Tugwell P, Welch V, Jolicoeur E, et al. Prevention of NSAID induced gastroduodenal ulcers (Cochrane review). In: The Cochrane Library, Issue 1. Oxford: Update software, 2003.

60 Schnitzer TJ, Kamin M, Olson WH. Tramadol allows reduction of naproxen dose among patients with naproxen-responsive osteoarthritis pain. Arthritis Rheum 1999:42:1370-7.

61 McAlindon TE, LaValley MP, Gulin JP, Felson DT. Glucosamine and chondroitin for treatment of osteoarthritis: a systematic quality assessment and meta-analysis. JAMA 2000;283: 1469-75.

62 Morreale P, Manopulo R, Galati M, Boccanera L, Saponati G, Bocchi L. Comparison of the antiinflammatory efficacy of chondroitin sulphate and diclofenac sodium in patients with knee osteoarthritis. J Rheumatol 1996;23:1385-91.

63 Mazieres B, Combe B, Phan Van A, Tondut J, Grynfeltt M. Chondroitin sulphate in osteoarthritis of the knee: a prospective, double blind, placebocontrolled multicenter clinical study. J Rheumatol 2001;28:173-81.

$64 \mathrm{Vaz}$ AL. Double blind clinical evaluation of the relative efficacy of ibuprofen and glucosamine sulphate. I The management of osteoarthritis of the knee in outpatients. Curr Med Res 1982;8:145-9.

65 Muller-Fassbender H, Bach GL, Haase W, Rovati LC, Setnikar I. Glucosamine sulphate compared to ibuprofen in osteoarthritis of the knee. Osteoarthritis Cartilage 1994;2:61-9.

66 Rindone JP, Hiller D, Collacott E, Nordhaugen N, Arriola G. Randomised, controlled trial of glucosamine for treating osteoarthritis of the knee. West J Med 2000;172:91-4.

67 Reginster JY, Deroisy R, Rovati LC, Lee RL, Lejeune E, Bruyere O, et al. Longterm progression of glucosamine sulphate on osteoarthritis progression: a randomised, placebo-controlled clinical trial. Lancet 2001;357:251-6.

68 Das A Jr, Hammad TA. Efficacy of a combination of FCHG49 $9^{\text {TM }}$ glucosamine hydrochloride, TRH1 $22^{\text {TM }}$ low molecular weight chondroitin sulphate and manganese ascorbate in the management of knee osteoarthritis. Osteoarthritis Cartilage 2000;8:343-50

69 Pelletier JP, Yaron M, Haraoui B, Cohen P, Nahir MA, Choquette D, et al. Efficacy and safety of diacerein in osteoarthritis of the knee. A double blind, placebo controlled trial. Arthritis Rheum 2000:43:2339-48.

70 Wobig M, Bach G, Beks P, Dickhut A, Runzheimer J, Schwieger G, et al. The role of elastoviscosity in the efficacy of viscosupplementaion for osteoarthritis of the knee: A comparison of hylan G-F 20 and a lower molecular weight hyaluronan. Clin Ther 1999;21:1549-62.

71 Dougados M, Nguyen M, Listrat V, Amor B. High molecular weight sodium hyaluronate (hyalectin) in osteoarthritis of the knee: a 1 year placebo controlled trial. Osteoarthritis Cartilage 1993;1:97-103.

72 Corrado EM, Peluso GF, Gigliotti S, De Durante C, Palmieri D, Savoia M, et al. The effects of intra-articular administration of hyaluronic acid on osteoarthritis of the knee: A clinical study with immunological and biochemical evaluations. Eur J Rheumatol Inflamm 1995;15:47-56.

73 Huskisson EC, Donnelly S. Hyaluronic acid in the treatment of osteoarthritis of the knee. Rheumatology (Oxford) 1999:38:602-7.

74 Carrabba M, Paresce E, Angelini M, Perbellini A. The safety and efficacy of different dose schedules of hyaluronic acid in the treatment of painful osteoarthritis of the knee with joint effusion. Eur J Rheumatol Inflamm $1995 ; 15: 25-31$.

75 Listrat V, Ayral X, Patarnello F, Bonvarlet JP, Simonnet J, Amor B, et al. Arthroscopic evaluation of potential structure modifying activity of hyaluronan (Hyalgan) in osteoarthritis of the knee. Osteoarthritis Cartilage 1997;5:153-60.

76 Lohmander LS, Dalen N, Englund G, for the Hyaluronan Multicentre Trial Group. Intra-articular hyaluronan injections in the treatment of osteoarthritis of the knee: a randomised, double blind, placebo-controlled multicentre trial. Ann Rheum Dis 1996;55:424-31.

77 Lussier A, Cividino AA, McFarlane CA, Olszynski WP, Potashner WJ, De Medicis R. Viscosupplementation with Hylan for the treatment of osteoarthritis: findings from clinical practice in Canada. J Rheumatol 1996;23:1579-85.

78 Dieppe PA, Sathapatayavongs B, Jones HE, Bacon PA, Ring EF. Intra-articular steroids in osteoarthritis. Rheumatol Rehabil 1980;19:212-17.

79 Ravaud P, Moulinier L, Giraudeau B, Ayral X, Guerin C, Noel E, et al. Effects of joint lavage and steroid injection in patients with osteoarthritis of the knee. Results of a multicenter, randomised, controlled trial. Arthritis Rheum 1999;42:475-82

80 Frankel S, Williams M, Nanchahal K, Coast J. Epidemiologically based needs assessment: total hip and knee joint replacement. HCEU report for the Department of Health, University of Bristol, 1990.

81 Chard J, Lohmander S, Smith C, Scott D. Osteoarthritis. In: Godlee F, ed. Clinical evidence. A compendium of the best evidence for effective health care. London: BMJ Publishing Group, 2002;issue 8:1212-37.

82 Manusco CA, Ranwat CS, Esdaile JM, Johanson NA, Charlson ME. Indications for total hip and total knee arthroplasties. Results of orthopaedic surveys. J Arthroplasty 1996;1:34-46. 